\title{
Bird feathers as potential sources of pathogenic microorganisms: a new look at old diseases
}

\author{
Andrzej Miskiewicz $(\mathbb{D} \cdot$ Paweł Kowalczyk - Sanaa Mahdi Oraibi • \\ Krystyna Cybulska • Anna Misiewicz
}

Received: 14 December 2017 / Accepted: 9 February 2018/Published online: 19 February 2018

(C) The Author(s) 2018. This article is an open access publication

\begin{abstract}
This article describes methods of treatment for avian zoonoses, modern antibiotic therapy and drug resistance of selected pathogens, which pose a threat to the population's health. A tabular form has been used to present the current data from the European Union from 2011 to 2017 regarding human morbidity and mortality and the costs incurred by national health systems for the treatment of zoonoses occurring in humans and animals. Moreover, the paper includes descriptions of selected diseases, which
\end{abstract}

Andrzej Miskiewicz and Paweł Kowalczyk have contributed equally to this work.

A. Miskiewicz

Department of Periodontology and Oral Diseases, Medical University of Warsaw, 18 Miodowa St., 00-246 Warsaw, Poland

P. Kowalczyk ( $\square)$

Department of Animal Nutrition, The Kielanowski Institute of Animal Physiology and Nutrition, Polish

Academy of Sciences, Jabłonna, Poland

e-mail: p.kowalczyk@ifzz.pl

S. M. Oraibi · K. Cybulska

Department of Chemistry, Microbiology and

Environmental Biotechnology, Faculty of Environmental

Management and Agriculture, West Pomeranian

University of Technology, Słowackiego 17 Str.,

71-434 Szczecin, Poland

A. Misiewicz

Institute of Agricultural and Food Biotechnology,

Rakowiecka 36, 02-532 Warsaw, Poland indirectly affect birds. Scientists can obtain information regarding the occurrence of particular diseases, their aetiology, epidemiology, incubation period and symptoms caused by dangerous microorganisms and parasites. This information should be of particular interest for people who have frequent contact with birds, such as ornithologists, as well as veterinarians, farm staff, owners of accompanying animals and zoological workers. This paper presents a review used for identification and genetic characterization of bacterial strains isolated from a variety of environmental sources, e.g., bird feathers along with their practical application. We describe the bacterial, viral and fungal serotypes present on avian feathers after the slaughter process. This review also enables us to effectively identify several of the early stages of infectious diseases from heterogeneous avian research material.

Keywords Bacterial - Bird diseases - Pathogenic microorganisms · Viral and fungal serotypes

$\begin{array}{ll}\text { Abbreviations } & \\ \text { AI } & \text { Avian influenza } \\ \text { AISS } & \text { Aerobactin iron sequestering system } \\ \text { Amp } & \begin{array}{l}\text { Chromosomally encoded } \beta- \\ \text { lactamase of class C }\end{array} \\ \text { APEC } & \begin{array}{l}\text { Avian pathogenic Escherichia coli } \\ \text { ASC }\end{array} \\ & \text { Anthrax strain collection }\end{array}$




\begin{tabular}{|c|c|c|c|}
\hline \multirow[t]{2}{*}{ BIOCONTAM } & EFSA unit on biological hazards & $\begin{array}{l}\mathrm{pXO} \\
\mathrm{SNP}\end{array}$ & Bacillus anthracis Sterne plasmid \\
\hline & and contaminants & SNP & Single nucleotide polymorphism \\
\hline \multirow[t]{2}{*}{ BIOHAZ } & The panel on biological hazard & SRA & Single nucleotide repeat analysis \\
\hline & EFSA & Stx & Shiga toxin \\
\hline CAV & Chicken anaemia virus & Tox A & Toxin A \\
\hline CIA & Chicken infection anaemia virus & TRT & Infectious rhinotracheitis virus \\
\hline $\mathrm{Cdt}$ & Cytolethal distending toxin & UE & European Union \\
\hline CMY & Cephalomycinase gene & uidA & Beta-glucuronidase producing \\
\hline \multirow[t]{2}{*}{ CTX } & Cefotaxime-hydrolysing class A $\beta$ - & & strains \\
\hline & lactamase & uidB & Glucuronide carrier protein \\
\hline Dam & DNA adenine methylase & & homologue \\
\hline DNA & Deoxirybonucleic acid & VNTR & Variable number of tandem repeats \\
\hline \multirow[t]{2}{*}{ ECDC } & European Centre for Disease & $\operatorname{vrrA}-\mathrm{B},-\mathrm{C}$ & Variable repeat region $\mathrm{A},-\mathrm{B},-\mathrm{C}$ \\
\hline & Prevention and Control & WGS & Whole genome sequencing \\
\hline EHEC & $\begin{array}{l}\text { Enterohemorrhagic Escherichia } \\
\text { coli }\end{array}$ & ycfR & Putative outer membrane protein \\
\hline ehxA & Enterohaemolysin A & & \\
\hline EF 2 & Elongation factor 2 & & \\
\hline EFSA & European Food Safety Authority & Background & \\
\hline ESBL & Extended spectrum beta-lactamases & & \\
\hline
\end{tabular}

Increasing morbidity from zoonoses is a significant problem in terms of global health, and they are currently considered exotic in Europe. Zoonoses are infectious or parasitic diseases transmitted by animals to humans (Spahr et al. 2018). These infections as aetiological factors can develop in humans in several ways:

- by the digestive tract, where the microorganism gets into the body via infected feed (meat) or water, which is quite often in large-scale farming. Therefore, Escherichia and Salmonella transmission to people occurs mainly through ingestion or frequent contact with infected birds. The above microorganisms can live in the external environment for a long period of time without damage to the pathogenic properties.

- by skin laceration; a break in the continuity of the skin promotes infection by pathogens of the staphylococci and streptococci families. In addition, the infection is intensified by the release of toxins into the host system.

NCD Newcastle disease

norV NADH:(flavo)rubredoxin reductase

OIE World Organisation for Animal

Health

ORF Open reading frame

pEAF Escherichia coli adherence factor

plasmid

PiCV Pigeon Circovirus

- by the respiratory system (by inhalation of dust in which the pathogens are raised); infection occurs through direct contact of a healthy individual with contaminated excretion or through indirect contact (low hygiene at the slaughterhouse) with contaminated faeces and secretion on bird feathers (HughJones and de Vos 2002). 
Humans are more susceptible to zoonoses carried by mammals than birds, and they share more diseases with them. This sharing is due to a higher degree of similarity between the intracellular environment of mammals (to which they belong), rather than birds. Many microorganisms need proper conditions and parameters to determine their host, for example, the presence of its receptor on the surface of the cells. These receptors can serve as a site for attachment and penetration into cells, which provides a pathway for the development of infection. The above situation determines the susceptibility of one animal species to a pathogen and resistance of another species. Vectors, such as insects, are also involved in the transmission of various pathogens, which may have an effect on the immune system. In the case of infecting a human with an avian zoonosis, the course of the disease is usually severe with general life-threatening symptoms. People who have been infected with an avian zoonosis require in-hospital treatment in isolation. Avian zoonoses in humans may end in death or a chronic disease requiring prolonged administration of antibiotics (Hugh-Jones and de Vos 2002).

Hence, the aim of this work is to present the aetiological factors of bird zoonoses, which are currently the most threatening to the European population. In addition, the epidemiological and economic analysis of the above infections in humans is presented. In general, zoonoses from birds can be divided by the type of the infectious agent: bacterial, viral and fungal.

\section{Selected bacterial zoonoses}

\section{Escherichia coli serotypes}

Bird feathers are the product of the epidermis that is colonized by serogroups of bacteria belonging to E. coli (Dho-Moulin and Fairbrother 1999). The most commonly isolated avian pathogenic $E$. coli strains are $\mathrm{O} 1, \mathrm{O} 2$ and $\mathrm{O} 78$, which are the primary cause of colicobacteriosis, inflammation of air sacs, polyserositis and bacteraemia (Mellata 2013). The factor predisposing an individual to the development of these infections is the PiCV (circovirus) infection, which affects moulting disorders but primarily damages the lymphatic tissue in the fabrician bursa, thymus, spleen and intestinal tract and leads to immunosuppression and development of secondary parenteral infections (Raue et al. 2005; Bougiouklis 2007).

Pathogenic E. coli are present in bird habitats, e.g., through dust and dried faeces, and may also be carried by house insects. The occurrence of colibacillosis in the flock occurs due to: keeping birds in poorly ventilated rooms, at a high density, and from malnutrition or overheating. Factors conducive to the development include immunodeficiency virus (e.g., chicken infectious anaemia virus, reo- and adenovirus infections), nutritional background (the presence of mycotoxin in the feed) and environmental factors (e.g., harmful gas admixtures: ammonia and hydrogen sulphide). The most important virulence factors of E. coli colonizing bird feathers are fimbriae $\mathrm{F} 1$ and $\mathrm{P}$, aerobactin iron sequestering system and temperaturesensitive haemagglutinin (Kobayashi et al. 2010). These virulence factors promote the development of generalized infections and inhibit phagocytosis in poultry lung alveoli (in case of E. coli aspiration) (Stathopoulos et al. 1999). The strains IAI39 and 536 with serotypes O7:K1 and O6:K15:H31, respectively, are the aetiological agents of pyelonephritis (ExPEC). Other strains, such as Sakai, EDL933 (O157:H7 serotype), CB9615 (O55:H7 serotype), APEC01 (01 serotype) and E2348/69 (O127:H6 serotype), are responsible for causing diarrhoea with symptoms of colicobacteriosis and secondarily of colicoseptemia (Table 1). Among the carriers of E. coli strains producing Shiga toxin O157 (EC4115, EDL933, Sakai and TW14359, SS17, and SS52), we can distinguish the group determined as super-shedders, which is contamination of $\mathrm{O} 157 \geq 10^{4} \mathrm{CFU} / \mathrm{g}$ (Ferens and Hovde 2011). In addition, due to the genomic similarity in the sequence length (5.49-5.53 Mb), G + C (50.4-50.5\%) and mean length of ORF (856-898 bp) of $E$. coli strains, RFLP does not enable the identification of a specific serotype. The analysis of bacterial pathogens in breeding and wild birds permits proper clinical diagnostics in human zoonotic diseases (Table 1).

Infections with Gram-negative bacteria of birds and humans continue to be a major problem in the diagnosis, prophylaxis and treatment of humans and animals. With the introduction of large-scale poultry farming, the incidence of infections caused by $E$. coli and Salmonella has increased. Factors favouring this phenomenon are the intensification of poultry farming 
Table 1 Summary presentation of E. coli strains including serotype, strain virulence and genetic characteristics

\begin{tabular}{|c|c|c|c|c|c|}
\hline $\begin{array}{l}\text { E. coli } \\
\text { strain name }\end{array}$ & Serotype & Pathotype & Genotype & Antibiotic resistance & Reference \\
\hline K 12 & HB101 O16 & Commensal & MG1655 & Kanamycin & $\begin{array}{l}\text { Blattner et al. (1997), Uma et al. } \\
\text { (2009) and Bose et al. (2017) }\end{array}$ \\
\hline C2834 & $\mathrm{O} 2$ & Enterinvasive & $i p a H+$ & $\begin{array}{l}\text { Ampicillin, } \\
\text { Chloramphenicol, TSX }\end{array}$ & Rosario et al. (2005) \\
\hline $\begin{array}{l}\text { DSM } \\
30083^{\mathrm{T}}\end{array}$ & $\mathrm{O} 1: \mathrm{K} 1: \mathrm{H} 7$ & $\begin{array}{l}\text { Uninary tract } \\
\text { infections }\end{array}$ & $\mathrm{U} 5 / 41^{\mathrm{T}}$ & $\begin{array}{l}\text { Hydrphobic antibiotic, } \\
\text { amingli, } \\
\text { aminoglycosides, } \\
\text { chloramphenicol }\end{array}$ & Meier-Kolthoff et al. (2014) \\
\hline $\begin{array}{l}\text { Sakai } \\
\text { Lineage I }\end{array}$ & O157:H7 & Diarrhoea & $\begin{array}{l}\text { stx } 2 c(v h- \\
b), \text { st } x 2 a / \\
\text { saalehxA }\end{array}$ & $\begin{array}{l}\text { B-lactams, } \\
\text { aminoglycosides }\end{array}$ & $\begin{array}{l}\text { Hayashi et al. (2001) and Brusa et al. } \\
\text { (2017) }\end{array}$ \\
\hline SS17 & O157:H7 & HUS & ycfR & Puromycin, acriflavine & $\begin{array}{l}\text { Andrews et al. (1997) and Cote et al. } \\
\text { (2015) }\end{array}$ \\
\hline SS52 & $\begin{array}{l}\text { O157nonH7(H16, } \\
\text { H26, H39) }\end{array}$ & pEAF & $\begin{array}{l}f i c \mathrm{H}, c d t \\
\quad s t x 2_{a}\end{array}$ & B-lactams, tellurite & $\begin{array}{l}\text { Katani et al. (2015) and Ferdous et al. } \\
\text { (2016) }\end{array}$ \\
\hline $\begin{array}{l}\text { TW14359, } \\
\text { Lineage } \\
\text { II }\end{array}$ & $\begin{array}{l}\mathrm{O} 157, \mathrm{O} 26: \mathrm{H} 11 \\
\mathrm{O} 103: \mathrm{H} 2\end{array}$ & HUS & $\begin{array}{l}\text { stx } 1, \text { stx } 2 c, \\
\quad \operatorname{norV}\end{array}$ & B-lactams, chlorine & $\begin{array}{l}\text { Batisson et al. (2003), Palaniappan } \\
\text { et al. (2006), Deng et al. (2011) and } \\
\text { Izac et al. (2017) }\end{array}$ \\
\hline $\begin{array}{l}\text { EC4115, } \\
\text { Lineage } \\
\text { II }\end{array}$ & O157:H7 & EHEC & $\operatorname{gad} \beta$ & ESBL & $\begin{array}{l}\text { Zhang et al. (2007) and Winkler et al. } \\
\text { (2015) }\end{array}$ \\
\hline $\begin{array}{l}\text { EDL933, } \\
\text { Lineage I }\end{array}$ & O157:H7 & EHEC & $\begin{array}{l}\text { dam, uidA, } \\
\text { uidB, }\end{array}$ & $\begin{array}{l}\text { Carbenicillin, } \\
\text { ampicillinstreptomycin }\end{array}$ & $\begin{array}{l}\text { Foster et al. (2013) and Carone et al. } \\
\text { (2014) }\end{array}$ \\
\hline
\end{tabular}

in a limited space and gaseous and microbiological pollution. Birds that are kept in difficult conditions are subjected to destructive stress, which interferes with proper immune reaction.

The presence of stress factors significantly affects the birds due to the suppression of the immune system. Therefore, in the cases of pathogen exposure, which are most commonly viruses or bacteria, there is an increased incidence in poultry. In the case of unfavourable sanitary conditions, the subjects are infected by microorganisms through

(i) the digestive tract; the most common infections are Gram-negative bacteria by ingestion of contaminated water or poultry feed. Bacteria from the genus Salmonella and E. coli can survive in the environment for long periods of time and gain virulent properties in the event of a weakened immune system of the birds.

(ii) the respiratory tract; the most common viral infections are passed by the respiratory tract
(Paramyxoviridae and Hepadnaviridae) by droplet infection under conditions of excessive poultry density.

(iii) the damaged skin; infections caused by inoculation of damaged skin are usually caused by Gram-positive bacteria or by ingestion of feed containing toxins, which are usually staphylococci.

Poultry mycoplasmosis-Mycoplasma gallisepticum is an often diagnosed disease on poultry farms that occurs in chickens, turkeys, peacocks and pheasants. This disease induces two types of disease: sinusoidal and mixed mycoplasma infection (Mercia 2001; Hennigan et al. 2012). The most sensitive are chickens and turkeys between 6 and 10 weeks of age, especially in large breeding farms. Mycoplasma synoviae occurs especially in chickens and turkeys. This disease primarily causes joint infection. Birds from 2 to 20 weeks are the most sensitive to it. Mycoplasma meleagridis primarily occurs in turkeys and peacocks. It causes inflammation of air sacs. The 
most sensitive are turkeys aged 3-4 months; however, the condition also affects older birds. Mycoplasma anatis and Mycoplasma anseris are present in ducks and geese and cause disease symptoms of the respiratory system.

Clinical manifestations occur in birds from 3 weeks of age. The losses mainly relate to reproductive and commodity stock chicken and broiler chickens and turkey broilers. Infection is most often aerogenous through the respiratory system; mycoplasma penetrates the air sacs and lungs and causes inflammation (Mercia 2001; Thomas et al. 2007; Hennigan et al. 2012). From the respiratory system, the mycoplasma penetrates the bloodstream and spreads throughout the body. Mycoplasmas have an exceptional ability for parent-to-offspring transmission. The abovementioned is crucial in spreading the disease in the flock. After hatching, chickens are already infected by nets, which transmit Mycoplasma to the yolks. After hatching, pathogens are capable of multiplying and spreading within the hatching organism. Mycoplasmosis, if present for the first time in the flock, most often stays for an extended period of time, which is why it is a very serious problem in breeding poultry. Mycoplasma infection is often complicated with the addition to other pathogens, e.g., E. coli, Haemophilus paragallinarum, or viruses attacking the upper respiratory tract (Thomas et al. 2007). A complication in turkeys can be infection with infectious rhinotracheitis virus (TRT). Mycoplasma usually colonizes the surface of the mucous membranes of the respiratory and urinary tracts of various animal species. A total of 17 species of mycoplasmas have been isolated from hospitalized humans. The most important mycoplasmas causing human infections are Mycoplasma pneumoniae and other species from the Mycoplasmataceae family-Mycoplasma hominis, Ureaplasma urealyticum, and Ureaplasma parvum.

In European Union countries, there are programmes to eliminate the poultry infected with mycoplasmas from breeding based on serological tests. Despite the large expenditure and use of poultry flock release programmes, mycoplasmal infections have not been fully eradicated for years. However, the use of preventive vaccines significantly reduces the occurrence of disease in the flock (Thomas et al. 2007).

Pseudotuberculosis is a bacterial disease caused by Yersinia pseudotuberculosis. In birds, the disease occurs at any age, and young birds are very sensitive.
Stress, worming, low hygiene, and vitamin deficiencies are also factors that predispose birds. Due to low economic value, there is only slight attention paid to the disease (Achtman et al. 1999; Robins-Browne and Hartland 2003; Lindler 2004; Carnoy et al. 2005). The sources of infection are wild and domestic birds and rodents. Infection occurs through the digestive tract from infected food and water. The pathogen can also penetrate damaged skin. The incubation period is 2-6 days. The disease is usually chronic, characterized by aversion of birds to motion, loss of appetite, diarrhoea, paralysis of the wings and lameness (Carnoy et al. 2005). Bird tuberculosis is mainly transmitted by air on small particles of mucus and may directly infect humans, as well. The aetiological agent of tuberculosis is Mycobacterium tuberculosis. The direct infection occurs when the individual susceptible to infection collects mycobacteria in the lungs in which they can multiply and give rise to infection. Bird treatment (high doses of tetracycline, fluoroquinolones and sulphonamides with trimethoprim) should always be combined to maintain proper hygienic conditions, rearing, and proper feeding.

Campylobacteriosis is a disease caused members of the genus Campylobacter, most commonly Campylobacter jejuni. These bacteria occur in the gastrointestinal tract of many animal species both domestic and wild. Studies have shown that the abovementioned bacteria play a significant role in system disorders of the digestive tract (Ryan and Ray 2004; Moore et al. 2005; Vandamme et al. 2006). An important reservoir for the disease is both breeding and wild birds, which may be entirely infected. Campylobacter infections in birds can develop as an asymptomatic or gastrointestinal tract infection. The intestinal form presents with the following symptoms: watery diarrhoea, weight loss and the worsening use of feed. In the case of Campylobacter infection, laying hens are recorded with reduced laying and hatching. It is worth noting that in recent years, Campylobacter has become more commonly known as a zoonosis than Salmonella (Vandamme et al. 2006). Human infection occurs through the intake of raw or undercooked infected meat, usually poultry, which leads to infections of the digestive tract, stomach and intestines. The acute, inflammatory diarrhoea most often caused by Campylobacter jejuni (90-95\% of all infections caused by Campylobacter species) and Campylobacter coli 
(approximately 5\% of infections) is accompanied by severe abdominal pain.

\section{Salmonella infections}

In 2016, an increase in Salmonella infections was seen in the European Union. Bacterial genome analysis from samples collected from 260 patients infected with Salmonella showed two separate subspecies, which have a partially common genome sequence. Multiple locus variable-number tandem repeat (MLVA) analysis revealed two fingerprints of Salmonella isolates: 2-9-7-3-2 and 2-9-6-3-2. Salmonella enteritidis is the most commonly detected serovar, which is the aetiological factor responsible for causing non-typhoidal Salmonellosis.

Infection with the above types is most likely through contact with feathers and poultry faeces. Following the directive of the European Union (EC No. 2160/2003) regulating the conditions of poultry breeding and the sanitary conditions of the slaughterhouse, the number of infections in humans in the European Union is stable between 30,000 and 40,000. However, it is notable that two new genetically different types of Salmonella responsible for 112 (MLVA 2-9-7-3-2) and 148 (MLVA 2-9-6-3-2) infections in humans are the cause of hospitalization and death. Based on the data collected in all of the EU countries, it was observed that two types of $S$. enteritidis, MLVA 2-9-7-3-2 and 2-9-6-3-2 phage type 8 , of avian origin are the aetiological factors of Salmonellosis other than typhoid fever (non-typhoidal Salmonellosis) in $6.4 \%$ of the cases of Salmonella infections (EFSA, ECDC 2015-2016). The Whole Genome Sequencing (WGS) analysis observed that the Enteritidis serovar is responsible for $40 \%$ of the infections.

In humans, the abovementioned serovar was responsible for over 90,000 infections throughout the European Union in 2011-2013. It is alarming that the mortality rate increased from $0.14 \%$ in 2013 to $0.24 \%$ in 2015 and almost doubled the number of hospitalizations from 7841 to 12,353 in 2015 (Table 2). Despite the constant number of non-typhoidal Salmonellosis infections, there is a growing concern regarding the increasing number of hospitalizations for Salmonella-induced zoonoses and the rising costs of the national health systems linked to it. The severity of infection, emerging genetic variants, and the difficulty of dealing with bird-related diseases in humans can have a significant impact on poultry breeding. Resistance to antibiotic treatment of Salmonellosis of bird origin is due to its high resistance (high multi-drug resistance (MDR)) for classic antibiotics used in the poultry industry. The MDR of the isolated bacteria among the broilers is $56 \%, 73 \%$ in turkeys, and the MDR in pigs is only $38 \%$ (JIACRA). The abovementioned condition results from the increasing resistance of poultry colonizing bacteria in industrial breeding, including Salmonella and E. coli, on fluoroquinolones, macrolides and tetracyclines (JIACRA and EFSA). An equally important threat to humans is the transmission of antibiotic resistance genes. Infection with Salmonella of avian origin spreads the ESBL/AmpC gene, which is especially common in poultry and is a cause of resistance to penicillin and cephalosporins. However, the plasmid mediated transmission of integrons, such as ${ }^{\text {bla }} \mathrm{CMY}_{2}$ and ${ }^{\text {bla }} \mathrm{CTX}-\mathrm{M}_{1,3,14}$, observed for the first time in the US is responsible for resistance to cephamycins and monobactams (Reich et al. 2013). Therefore, the use of the above antibiotic classes in poultry farming should be avoided at this time, especially since fluoroquinolones and tetracyclines are widely used in human treatment and are the antibiotics of the most common infections in the respiratory and urinary tract. It seems optimistic that there is no relation to the use of feed containing cephalosporins of 3rd and 4th generation with antibiotic resistance among bacteria, which are the aetiological factors of bird zoonoses, especially the recently isolated MLVA subtypes 2-9-7-3-2 and MLVA 2-9-63-2 of S. enteritidis. The third generation of cephalosporins is referred to as "extremely important in the treatment of humans and animals" (Cohen et al. 2012; Liebana et al. 2013); hence, the use of cefepime and/or cefotaxime appears to be justified at present (Table 2).

A large number of breeding birds accumulated on a small area in a slaughterhouse promotes the intensification of the stressors. The phenomenon of stress encountered in large-scale poultry farming may have a variety of sources. This stress usually involves too many birds, poor feeding and poor maintenance (a microclimate with gaseous, particulate and microbial contamination). Birds exposed to such stressful environments are more likely to suffer from several diseases (Cohen et al. 2012; Liebana et al. 2013). 
Table 2 Incidence, hospitalization and mortality confirmed in humans for Salmonellosis and the total for all zoonoses in the European Union countries in 2013 and 2015

\begin{tabular}{|c|c|c|c|c|c|c|c|}
\hline year & $\begin{array}{l}\text { Type of } \\
\text { zoonoses }\end{array}$ & $\begin{array}{l}\text { Number of } \\
\text { confirmed } \\
\text { human cases }\end{array}$ & $\begin{array}{l}\text { Percentage of all cases } \\
\text { of Salmonellosis among } \\
\text { all zoonoses }\end{array}$ & $\begin{array}{l}\text { Hospitalisation } \\
\text { reported cases }\end{array}$ & $\begin{array}{l}\text { Reported } \\
\text { deaths }\end{array}$ & $\begin{array}{l}\text { Percentage of deaths due } \\
\text { to Salmonellosis among } \\
\text { all zoonoses }\end{array}$ & $\begin{array}{l}\text { Case } \\
\text { fatality }^{\mathrm{a}}\end{array}$ \\
\hline \multirow[t]{2}{*}{2013} & Salmonellosis & 82.694 & NA & 7.841 & 59 & NA & 0.14 \\
\hline & $\begin{array}{c}\text { Total no of } \\
\text { zoonoses }\end{array}$ & 313.636 & $26.6 \%$ & 22.199 & 344 & $17.1 \%$ & 0.18 \\
\hline \multirow[t]{2}{*}{2015} & Salmonellosis & 94.625 & NA & 12.353 & 126 & NA & 0.24 \\
\hline & $\begin{array}{c}\text { Total no of } \\
\text { zoonoses }\end{array}$ & 342.651 & $27.6 \%$ & 34.412 & 470 & $26.8 \%$ & 0.23 \\
\hline
\end{tabular}

Based on EFSA, BIOHAZ team and BIOCONTAM Unit 2013-2015 data and EU summary report on zoonoses, zoonotic agents; 2016 (https://doi.org/10.2903/jefsa.2016.4634)

NA Not applicable

${ }^{\mathrm{a}}$ Weighted arithmetic mean

\section{Bacillus infections}

Bacteria belonging to the genus Bacillus are Grampositive rod-shaped and have the ability to form endospores. Bacillus bacteria are characterized by oxygen or relatively anaerobic metabolism and hexoses, such as glucose, are broken down into pyruvic acid (Coker et al. 2002; Lista et al. 2006). In terms of metabolic strategies, they belong to the group of chemoorganotrophs. Most bacteria of the genus Bacillus are recognized by the Food and Drug Administration as GRAS (generally recognized as safe); however, one of the representatives of this type of bacteria, Bacillus anthracis, is the aetiological agent of anthrax. The disease is one of the most crucial zoonoses not only for humans but also for carnivorous mammals. Anthrax strains are observed in water and soil, and they are transported by flies (Muscidae) on food. In addition, bacteria can activate even after a hundred years from spores (Maho et al. 2006; Pilo et al. 2008). People are infected with anthrax by ingesting contaminated meat or water and by skin contact with contaminated material and pulmonary anthrax by inhalation of spores. From birds, the disease is most often transmitted through direct contact with the skin and its appendages, such as feathers and claws, in large-scale poultry farms and in slaughterhouses. Anthrax still poses a danger to public health and can be a source of material loss to livestock farmers (Mohammed et al. 2002). In general, the anthrax present in birds is due to the environment of life, i.e., in free-living and breeding birds (Maho et al. 2006; Pilo et al. 2008). Free-living birds are most often infected in warm climates due to the process of sporulation, which occurs above $9-12{ }^{\circ} \mathrm{C}$. Anthrax is most commonly found in the feathers of the Common ostrich, Struthio camelus, with the natural biotope the semi-deserts of Africa. Conversely, in poultry breeding, anthrax occurs primarily in the form of compact spores in chicken feed and water tanks. Anthrax has also been found in pigeon feathers; therefore, the breeding of poultry birds should be isolated from wild birds. The course of anthrax in birds is violent; the lungs have a dark colour, hyperaemia and pulmonary oedema occurs, and haemorrhagic intestinal inflammation and necrosis foci are found in the internal organs (Kruse et al. 2004). According to the current knowledge, anthrax is classified based on sequencing and DNA analysis. Presently, 89 genotypes are known, which we distinguish based on the alleles of $\operatorname{vr} A$, $v r r B_{1-2}$, and $v r r C_{1-2}$ genes and two loci on virulence plasmids (Keim et al. 2000; Coker et al. 2002; Lista et al. 2006; Ortatatli et al. 2012). Type A and B strains, and then the individual strains, are based on the following guidelines:

- Single nucleotide polymorphism (SNP) analysis to determine the phylogenetic group of bacteria,

- Multi-locus VNTR analysis (MLVA) to distinguish similar groups of partially shared sequences among the obtained isolates, 
- Single nucleotide repeat analysis (SRA) if the above methods were not able to differentiate the tested strains (Table 3).

Treatment and prevention against anthrax is based on the use of antibiotics: $\beta$-lactams, tetracyclines and fluoroquinolones. To date, B. anthracis ASC32 and ASC70 and 183 other strains (ASC32 pXO derived strains $_{1-/ 2+}$ ) have been observed to be resistant to penicillin (Turnbull et al. 2004; Beyer and Turnbull 2009). These strains were isolated from blood infected with anthrax, fertilizers used in horticulture and feed with bone meal. If resistance is not established, the antibiotic of choice should be vancomycin. MLVA-8 analysis based on open reading frame (ORF) markers: $v r r-A$ and $B_{1-2} C_{1-2} . \mathrm{CG}_{3}$ and plasmid DNA $\mathrm{pX} 0_{1-2}$ in correlation with the drug susceptibility is presented in Table 3.

Pseudomonas infections

Pseudomonas contains Gram-negative bacteria with a polar flagellum. Unlike the Bacillus genus, they do not form spores and effect the denitrification process (e.g., Pseudomonas fluorescens). Pseudomonas, in the same way as E. coli, metabolise hexoses via the EntnerDoudoroff pathway and obtain one molecule of ATP, $\mathrm{NADH}$ and NADPH as alternatives to the glycolysis pathway. Bacteria of this genus are mostly opportunistic pathogens, although we distinguish the absolute pathogens of animals and humans (Pseudomonas aeruginosa, P. cepacia, and P. maltophila). Pseudomonas malle $i$ and $P$. pseudomalle $i$ are the aetiological factors of glanders and melioidosis. People are infected most often by inhalation and by direct contact through damaged skin causing soft tissue infections. Pseudomonas are usually involved in severe complications from burns and postoperative wound infections as well as respiratory tract infections. The above-mentioned complications occur in patients who are frequently hospitalized and/or hospitalized for a long period of time: especially those treated for cystic fibrosis, gastrointestinal infection, and urinary tract infections (catheters); sinusitis; ocular corneal infection; and those mechanically ventilated (Schaberg et al. 1991; Elkin and Geddes 2003; Kumaran et al. 2010).

Infections last for approximately two weeks and often result in death. Pseudomonas type virulence factors include endotoxin $\left(\mathrm{LD}_{50} 300 \mu \mathrm{g}\right.$ intravenously in mice), toxin $\mathrm{A}$ (ToxA) $\mathrm{LD}_{50} 0.2 \mu \mathrm{g}$, heatstable haemolysin $\mathrm{LD}_{50} 5 \mathrm{mg}$, and leucocidin $\mathrm{LD}_{50}$ $0.4 \mu \mathrm{g}$. The most important factor for Pseudomonas virulence is toxin A (ToxA). ToxA is produced by 90\% of all Pseudomonas strains and the mean lethal dose in mice is $0.2 \mu \mathrm{g}$ per mouse. The toxic effect of ToxA is the inhibition of the elongation factor 2 (EF-2) by transferring the rest of the ADP-ribosyl coming from the nicotinamide adenine dinucleotide (NAD). The mechanism of action of ToxA is similar to that of the diphtheria toxin. In the case of human sepsis during infection with the ToxA strain of Pseudomonas, the survival chances are dramatically increased in those subjects initially exposed to Diphtheria producing ToxA due to the presence of the present antitoxin A antibodies (Elkin and Geddes 2003; Kumaran et al. 2010). P. aeruginosa together with Aeromonas hydrophila are the most common aetiologic factors of zoonoses of bird origin. The above bacteria, although they belong to two different taxonomic units, are characterized by common features: the biotope is the water environment (and also water at $20^{\circ} \mathrm{C}$ ). The above bacteria can be grown on common media (King Agar, thioglycollate), and when growing, they form $\beta$-haemolysis on the substrate with blood.

Viral diseases

\section{Marek's disease}

The most pest-prone species of poultry are primarily hens, quail and turkeys. The condition is caused by a virus belonging to the Herpesvirus genus. The way they penetrate the organism is through the respiratory system or gastrointestinal tract. Infection usually occurs immediately after hatching. The virus contained in the exfoliated warts of the pen still retains its virulence for more than 12 months after initiation. Infected birds show weight loss and paroxysmal symptoms. However, it often occurs that the course of this disease is very violent and no clinical symptoms were observed in humans (Ryan and Ray 2004; Koelle and Corey 2008; Johnston et al. 2011; Schiffer et al. 2014). 


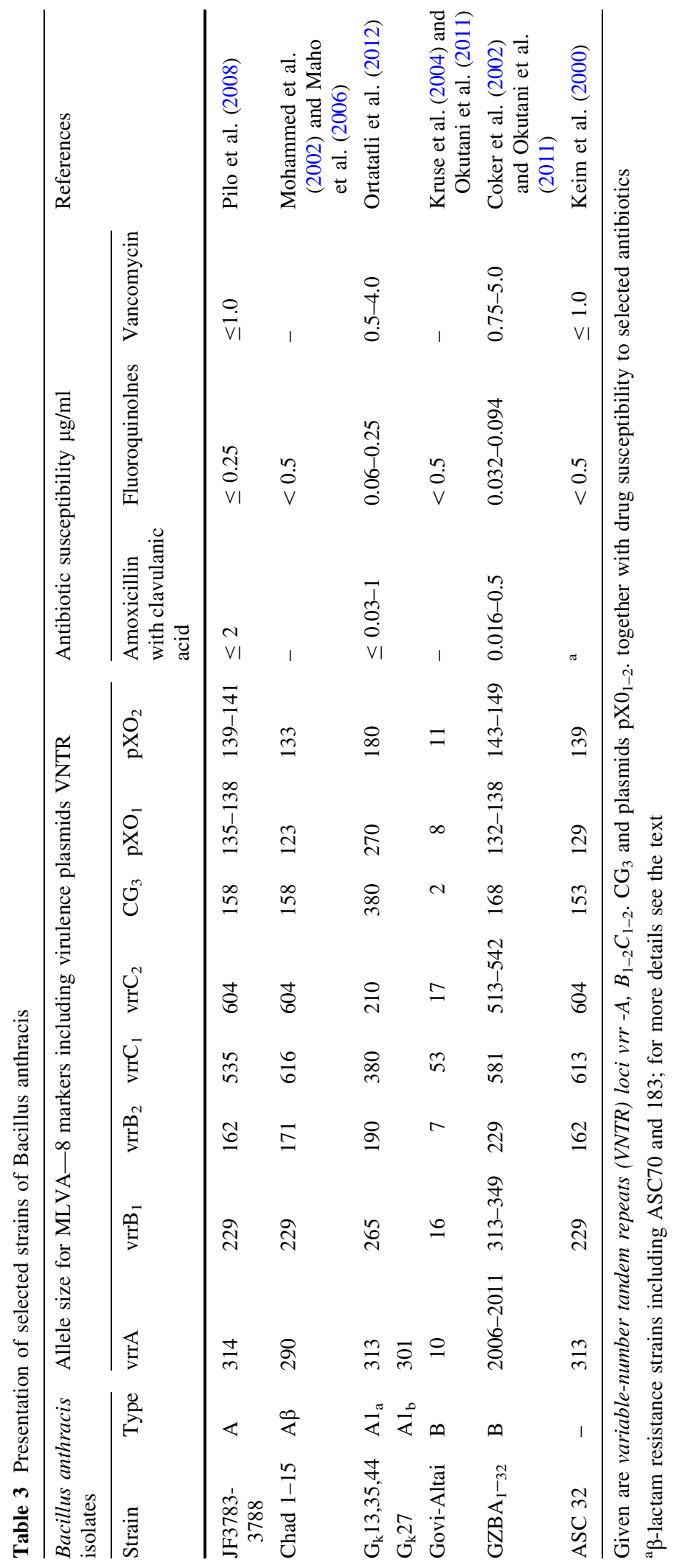


Newcastle disease

Newcastle disease is also called NCD. This disease is most often found in chickens and turkeys. Ducks and geese do not get sick but they can be carriers of the virus. The primary sources of infection are sick and dead birds (direct contact). Illness can also spread through equipment used on farms, cars, people, and wild birds (indirect contact). The infection comes through the respiratory and digestive tract and through damaged skin, conjunctiva and the mucous membrane (Csatary et al. 1999, 2000). The incubation period lasts a few days (generally 3-6 days). The virus, along with the blood, is transferred to all of the organs causing degeneration of the blood vessel walls and leading to effusion. The only protection against the dangerous virus that causes NCD is the regular vaccination of birds (Csatary et al. 1999, 2000). The disease is transmitted to humans by infected bird droppings and discharges from the beak and eyes, especially when working in poultry processing plants, among birds kept in a closure, for example, breeding chickens. Exposure of people to infected birds may cause mild conjunctivitis and flu-like symptoms, but the virus does not pose a threat to human health.

\section{Infectious bronchitis}

Chickens and pheasants are susceptible to infection from this disease. The disease is caused by a virus belonging to the genus Coronavirus. Initially, it was thought that the chicken disease is caused by a pathogenic, homogeneous antigenic strain, which is represented by the Massachusetts strain 41. However, the ability to create multiple variants differing from the original strain of the abovementioned led to the isolation of more than 30 serotypes and antigen variants, with the number steadily growing. Between birds, the infection spreads by the aerogenic route. The pathogen also moves between the henhouse and the farm. The incubation period is from 18 to $72 \mathrm{~h}$ (Cavanagh and Naqi 2003). In chickens, Infectious Bronchitis (IB) causes severe inflammatory lesions in the respiratory tract. It leads to the inflammation of the bronchial mucous membranes and the bronchial obstruction occurs as a result. As the disease progresses, the serious secretions obstruct the fork of the trachea leading to dyspnea and "breathing pumping". In adult birds, the egg-laying capacity is rapidly reduced (within 5-7 days), and the quality of the crust is crispy and discoloured with characteristic deformities. Secondary bacterial complications should be treated with antibiotics (Cavanagh and Naqi 2003). The only effective way to avoid IB losses is through systematic and preventive vaccination. Attenuated and inactivated vaccines are used in this case. Presently, serotypes of members 4/91 are recommended in Europe to provide prototype protection and protect birds against most other antigenic IB strains (Cavanagh and Naqi 2003).

\section{Avian influenza}

Avian influenza is one of the most devastating diseases in chickens and turkeys, although the virus can also infect birds (pheasants, partridges, and quail), ratites (ostriches and emu), parrots and sparrows. This disease is caused by a virus of the Orthomyxoviridae family. The most severe form of the disease, which was originally called "Highly Pathogenic Avian Influenza (HPAI)," is included in the World Organization for Animal Health (OIE) List A contagious animal diseases. An outbreak of this disease is recorded every few years around the world. It is likely due to the occurrence of indirect or direct contact of domestic poultry with wild water birds. Infection is caused by contact with faeces of sick birds and by secretions from their eyes and nostrils. It was found that the virus also occurs in the yolk and egg white. The infected eggs do not hatch chickens, but the content in the liquid egg white is highly contagious due to the presence of virions (Panigrahy et al. 1996; Perkins and Swayne 2002). In the case of high bird density at the breeding farms, the infection can be caused by droplets from infected birds but also by such things as contaminated equipment and by means of transport. The virus incubation period ranges from several hours for 2-3 days. For official control purposes, the maximum incubation period of HPAI is 21 days.

Development of natural AI infections in poultry includes two main clinical courses: HPAI and minimally virulent bird flu (LPAI). The first includes the following symptoms: rapid fall/loss of egg production, a soft eggshell, oedema and bruising, diarrhoea, falls may be sudden with no visible symptoms, and mortality can affect up to $100 \%$ of the flock, whereas during LPAI, the following may develop: respiratory 
symptoms (usually mild), diarrhoea and decreased egg production in laying hens. Bird mortality is low in this case and usually does not exceed 5\% although it can occur as a result of secondary infections or in young birds (occurrence of up to 97\%). In the case of detection of HPAI in poultry, the strategy of action is to quickly eliminate the source of infection in the shortest possible time by introducing strict quarantine and rapid extermination of the entire poultry population in the epidemic area and destruction of the contaminated products, materials and equipment. There is also a decontamination treatment that reduces the presence of the virus by isolating the infected farms (Panigrahy et al. 1996; Perkins and Swayne 2002).

\section{Infectious anaemia of chickens}

Infection mainly affects young chickens. The disease causes a highly resistant virus classified as Circovirus and designated as CAV (Chicken Anaemia Virus) or CIA (Chicken Infectious Anaemia Virus). The main way of spreading the virus of infectious anaemia is vertically transmitted infection. In this case, the infected pullets transmit the infection to their offspring. It is also possible to spread the infection, especially in young birds, by direct contact with a patient with clinical signs and an inoculated environment (e.g., equipment and clothing) (Miller et al. 2005; Schat 2009; Quinn et al. 2015).

\section{Infectious laryngotracheitis (ILT)}

Chickens and pheasants are susceptible to natural infections caused by a virus belonging to the Herpesviridae family. ILT is one of the diseases in List B of the Animal Diseases of the World Organization for Animal Health (OIE). Infection is caused by the contact of sick birds with healthy ones. In most cases, infectious laryngotracheitis is caused by the presence of ILT virus (Fenner et al. 2015). The incubation period ranges from 4 to 12 days, and birds show signs of respiratory symptoms. The larynx and trachea are grey and easy to separate and birds often suffer from suffocation. In the typical course of ILT, the daily drop is approximately $1 \%$ (Fenner et al. 2015). Humans are not usually affected by ILT due to the thermosensitivity virus. The virions are neutralized by food thermal processing.

\section{Chickenpox}

Avian pox is caused by a virus in chickens, turkeys, pheasants and species of wild birds. Avipoxvirus belongs to the Poxviridae family, and like the other viruses, they significantly affect the birds. The most common cause of infection is the introduction of infected individuals into the flock. Contaminated feed and water can also be a source of infection. During the summer, mosquitoes and flies can spread infections both in the flock and between farms (Macartney and McIntyre 2008). The incubation period lasts from 4 to 20 days. Two forms of disease have been reported: dermatitis and diphtheria. The disease lasts approximately 20-30 days. Chickenpox-induced falls are very different. In the case of dermatitis, the mortality is low (1-2\%) but diphtheria can reach 50\% (Macartney and McIntyre 2008). In humans, the infection spreads similar to nosocomial infections. The hallmark symptom of chickenpox is a rash. Before the pox appear, there is a general malaise sensation, fever, muscle aching, loss of appetite, in some cases, a feeling of nausea. Chickenpox generally resolves within a week or two without treatment. There is no cure but a vaccine can prevent it. In the United States, the chickenpox vaccine is routinely given to children.

Main fungal diseases

\section{Aspergillosis}

Aspergillosis is a group of conditions caused by Aspergillus fungi and most commonly by A. fumigatus. The disease may worsen the symptoms during other conditions in young chickens or may develop as a separate and chronic illness in the elderly. The severity of the symptoms depends on the amount of spores in the environment and the condition of the birds. The source of infection is primarily a poorly stored feed; however, the fungal spores can also be found in the mulch (mouldy straw, chips, and sawdust). Fungal respiratory infection constitutes a threat for poultry farming and comprises major cause of death in breeding birds. The disposing factor is unhygienic, dark, damp, poorly ventilated poultry houses and one-sided feeding with small amounts of vitamins (especially vitamin A) (Oglesbee 1997; Kearns 2003; Dallwig et al. 2007). The incubation period is from 1 to 10 days and depends on many 
factors (fungus species, route of infection, spore volumes, age and condition of the birds). Infected birds are less active, apathetic, weakened and emaciated, and they often stand with a slightly open beak. In addition, their appetite is reduced, but shortly before death it increases. In chickens with acute disease, one symptom is diarrhoea and death is preceded by the occurrence of convulsions. Paralysis of the neck may occur as well. The skin forms large and irregular scabs and often merges together. These scabs appear most often in the area of the ridge, which leads to falling of the feathers. Care should be taken to ensure the hygiene of the henhouse and the quality of the feed and litter and its proper storage. Human infection occurs by air on poultry farms from floating dust on which fungal spores occur. Inhaled from the air, fungal spores develop as pathogens in cases of underlying and severe systemic disease (e.g., tuberculosis, sarcoidosis, and AIDS). The spores penetrate the lung cavity and germinate and then form a compact biomass of mycelium. Consequently, the fungus releases toxins and allergy-causing antigens. Humans affected by the disease may show symptoms such as weight loss and chronic cough. In contrast, symptoms of extreme exhaustion occur later. Haemoptysis can occur in $50-80 \%$ of people affected by the disease (Oglesbee 1997; Kearns 2003; Dallwig et al. 2007).

\section{Candidiasis}

This disease is caused by Candida fungi. Candida albicans (isolated in approximately $95 \%$ of cases) is the most commonly encountered cause in poultry. Candidiasis has been reported in chickens, turkeys, guineafowls, pheasants, geese, pigeons, quail and ornamental birds such as parrots and peacocks. The infection most often occurs through contaminated litter, poor quality feed and water (James et al. 2006). The development time of the pathogen, from the time of infection to the onset of symptoms, ranges from 5 to 10 days. Symptoms associated with the disease are: reduced weight gain due to appetite suppression, deterioration in plumage quality and watery diarrhoea. Preventive measures should be based on a thorough disinfection and improved hygiene of rooms and food (James et al. 2006). There are more than 20 Candida species that can cause human infection, the most common of which is C. albicans. Symptoms of candidiasis vary depending on the area of the infected organism, and most often it develops in the mouth or throat as a result of inhaling contaminated air from enclosed farms and results in the feeling of a longlasting dry cough.

\section{Cryptococcus}

Cryptococcus blastospores are present in the digestive tract of birds in nature. Especially high concentrations occur in the intestine of the Columbidae bird family (e.g., pigeons). In the case of the undermined innate immune system, the blastospores overcome through the disrupted gut barrier resulting in avian cryptococcosis. Cryptococcus neoformans are isolated from the faeces of pigeons or land contaminated by their faeces. Fresh larvae do not usually develop C. neoformans infection due to high acidic $\mathrm{pH}$ in the digestive tract. However, the older bird excrements are excellent nutrients in which fungi can live for up to two years. Other species do not usually get sick because the maximum fungal growth temperature is $40{ }^{\circ} \mathrm{C}$ which is lower than that in birds (Hagen et al. 2015). Mammals, including humans, are vulnerable to infection; therefore, cryptococcosis is considered a zoonosis. The infection usually occurs through direct inhalation of spores into the nasal cavity. People are most likely to be infected with $C$. neoformans by inhalation in the form of aerosol spores from dried bird faeces (Hagen et al. 2015).

\section{Conclusions}

Transmission of the abovementioned pathogens from birds to mammals, especially humans, occasionally occurs. However, people who work professionally at bird slaughterhouses have a higher exposure, and these pathogens can be much more threatening. Nevertheless, following the outbreaks of avian influenza and Salmonella infections, preventive measures should be taken including transboundary infection-control strategies. The abovementioned pathogens are capable of developing serious systemic infections resulting in fatal conditions. Humans with undermined immune systems by acquired or congenital immunodeficiencies constitute a particularly vulnerable group for developing a lethal disease. Maintaining a good level of hygiene plays a fundamental role in the prevention of bird zoonoses. The occurrence of flu-like symptoms 
or acute food poisoning in these individuals after direct or indirect contact with birds should motivate them to seek medical attention.

Acknowledgements This research did not receive any specific grant from funding agencies in the public, commercial, or not-for-profit sectors.

\section{Compliance with ethical standards}

Conflict of interest The authors declare that they have no conflict of interest.

Ethical approval All of the applicable international, national, and institutional guidelines for the care and use of animals were followed. This article does not contain any studies with human participants performed by any of the authors.

Data availability The datasets generated and/or analysed during the current study are available from the corresponding author upon reasonable request.

Open Access This article is distributed under the terms of the Creative Commons Attribution 4.0 International License (http:// creativecommons.org/licenses/by/4.0/), which permits unrestricted use, distribution, and reproduction in any medium, provided you give appropriate credit to the original author(s) and the source, provide a link to the Creative Commons license, and indicate if changes were made.

\section{References}

Achtman M, Zurth K, Morelli G, Torrea G, Guiyoule A, Carniel E (1999) Yersinia pestis, the cause of plague, is a recently emerged clone of Yersinia pseudotuberculosis. Proc Natl Acad Sci USA 96:14043-14048. https://doi.org/10.1073/ pnas.96.24.14043

Andrews SC, Berks BC, McClay J, Ambler A, Quail MA, Golby P, Guest JR (1997) A 12-cistron Escherichia coli operon (hyf) encoding a putative proton-translocating formate hydrogenlyase system. Microbiology 143:3633-3647. https://doi.org/10.1099/00221287-143-11-3633

Batisson I, Guimond MP, Girard F, An H, Zhu C, Oswald E, Fairbrother JM, Jacques M, Harel J (2003) Characterization of the novel factor paa involved in the early steps of the adhesion mechanism of attaching and effacing Escherichia coli. Infect Immun 71:4516-4525. https://doi.org/10.1128/ IAI.71.8.4516-4525.2003

Beyer W, Turnbull PCB (2009) Anthrax in animals. Mol Aspects Med 30:481-489. https://doi.org/10.1016/j.mam. 2009.08.004

Blattner FR, Plunkett G 3rd, Bloch CA et al (1997) The complete genome sequence of Escherichia coli K-12. Science 277:1453-1462. https://doi.org/10.1126/science.277.5331. 1453

Bose T, Venkatesh KV, Mande SS (2017) Computational analysis of host-pathogen protein interactions between humans and different strains of enterohemorrhagic
Escherichia coli. Front Cell Infect Microbiol 7:128. https:// doi.org/10.3389/fcimb.2017.00128

Bougiouklis PA (2007) Avian circoviruses of the genus Circovirus: a potential trigger in Pigeon breeder's lung (PBL)/ Bird fancier's lung (BFL). Med Hypotheses 68:320-323. https://doi.org/10.1016/j.mehy.2006.07.020

Brusa V, Restovich V, Galli L et al (2017) Isolation and characterization of non-O157 Shiga toxin-producing Escherichia coli from beef carcasses, cuts and trimmings of abattoirs in Argentina. PLoS ONE 12:e0183248. https:// doi.org/10.1371/journal.pone.0183248

Carnoy C, Lemaitre N, Simonet M (2005) The superantigenic toxin of Yersinia pseudotuberculosis. In: Ladant D, Alouf JE, Popoff MR (eds) The comprehensive sourcebook of bacterial protein toxins, 3rd edn. Academic Press, London, pp 862-871

Carone BR, Xu T, Murphy KC, Marinus MG (2014) High incidence of multiple antibiotic resistant cells in cultures of in enterohemorrhagic Escherichia coli O157:H7. Mutat Res 759:1-8. https://doi.org/10.1016/j.mrfmmm.2013.11. 008

Cavanagh D, Naqi SA (2003) Infectious bronchitis. In: Saif YM (ed) Diseases of poultry, 11th edn. Iowa State University Press, Ames, IA, pp 101-120

Cohen SJ, van den Munckhof T, Voets G, Scharringa J, Fluit A, Hall ML (2012) Comparison of ESBL contamination in organic and conventional retail chicken meat. Int J Food Microbiol 154:212-214. https://doi.org/10.1016/j. ijfoodmicro.2011.12.034

Coker PR, Smith KL, Hugh-Jones ME (2002) Antimicrobial susceptibilities of diverse Bacillus anthracis isolates. Antimicrob Agents Chemother 46:3843-3845. https://doi. org/10.1128/AAC.46.12.3843-3845.2002

Cote R, Katani R, Moreau MR et al (2015) Comparative analysis of super-shedder strains of Escherichia coli O157:H7 reveals distinctive genomic features and a strongly aggregative adherent phenotype on bovine rectoanal junction squamous epithelial cells. PLoS ONE 10:e116743. https://doi.org/10.1371/journal.pone. 0116743

Csatary LK, Moss RW, Beuth J, Torocsik B, Szeberenyi J, Bakacs T (1999) Beneficial treatment of patients with advanced cancer using a Newcastle disease virus vaccine (MTH-68/H). Anticancer Res 19:635-638

Csatary LK, Csatary E, Moss RW (2000) Re: scientific interest in newcastle disease virus is reviving. J Natl Cancer Inst 92:493-494. https://doi.org/10.1093/jnci/92.6.493

Dallwig R, Hanley C, Ballegeer E, Steinberg H (2007) What is your diagnosis? J Am Vet Med Assoc 231:205-206. https://doi.org/10.2460/javma.231.2.205

Deng K, Wang S, Rui X, Zhang W, Tortorello ML (2011) Functional analysis of ycfR and ycfQ in Escherichia coli O157:H7 linked to outbreaks of illness associated with fresh produce. Appl Environ Microbiol 77:3952-3959. https://doi.org/10.1128/AEM.02420-10

Dho-Moulin M, Fairbrother JM (1999) Avian pathogenic Escherichia coli (APEC). Vet Res 30:299-316

Elkin S, Geddes D (2003) Pseudomonal infection in cystic fibrosis: the battle continues. Expert Rev Anti Infect Ther 1:609-618. https://doi.org/10.1586/14787210.1.4.609 
Fenner F, Gibbs E, Paul J, Murphy F, Rott A, Studdert R, Michael J, David O (2015) Veterinary virology, 2nd edn. Academic Press, New York

Ferdous M, Kooistra-Smid AM, Zhou K, Rossen JW, Friedrich AW (2016) Virulence, antimicrobial resistance properties and phylogenetic background of non-H7 enteropathogenic Escherichia coli O157. Front Microbiol 7:1540. https://doi. org/10.3389/fmicb.2016.01540

Ferens WA, Hovde CJ (2011) Escherichia coli O157:H7: animal reservoir and sources of human infection. Foodborne Pathog Dis 8:465-487. https://doi.org/10.1089/fpd.2010. 0673

Foster PL, Hanson AJ, Lee H, Popodi EM, Tang H (2013) On the mutational topology of the bacterial genome. G3 (Bethesda) 3:399-407. https://doi.org/10.1534/g3.112. 005355

Hagen F, Khayhan K, Theelen B, Kolecka A, Polacheck I, Sionov E, Falk R, Parnmen S, Lumbsch HT, Boekhout T (2015) Recognition of seven species in the Cryptococcus gattii/Cryptococcus neoformans species complex. Fungal Genet Biol 78:16-48. https://doi.org/10.1016/j.fgb.2015. 02.009

Hayashi T, Makino K, Ohnishi M et al (2001) Complete genome sequence of enterohemorrhagic Escherichia coli O157:H7 and genomic comparison with a laboratory strain K-12. DNA Res 8:11-22. https://doi.org/10.1093/dnares/8.1.11

Hennigan SL, Driskell JD, Ferguson-Noel N, Dluhy RA, Zhao Y, Tripp RA, Krause DC (2012) Detection and differentiation of avian mycoplasmas by surface-enhanced Raman spectroscopy based on a silver nanorod array. Appl Environ Microbiol 78:1930-1935. https://doi.org/10.1128/ AEM.07419-11

Hugh-Jones ME, de Vos V (2002) Anthrax and wildlife. Rev Sci Tech 21:359-383. https://doi.org/10.20506/rst.21.2.1336

Izac JR, Oliver LD Jr, Earnhart CG, Marconi RT (2017) Identification of a defined linear epitope in the OspA protein of the Lyme disease spirochetes that elicits bactericidal antibody responses: implications for vaccine development. Vaccine 35:3178-3185. https://doi.org/10.1016/j.vaccine. 2017.04.079

James WD, Berger TG, Elston DM (2006) Andrews' diseases of the skin: clinical dermatology. Saunders, Philadelphia

Johnston C, Koelle DM, Wald A (2011) HSV-2: in pursuit of a vaccine. J Clin Invest 121:4600-4609. https://doi.org/10. 1172/jci57148

Katani R, Cote R, Garay JAR, Li L, Arthur TM, DebRoy C, Mwangi MM, Kapur V (2015) Complete genome sequence of SS52, a strain of Escherichia coli O157:H7 recovered from supershedder cattle. Genome Announc 3:e01569. https://doi.org/10.1128/genomeA.01569-14

Kearns KS (2003) Avian aspergillosis. In: Kearns KS, Loudis B (eds) Recent advances in avian infectious diseases. Int Vet Inf Serv, Ithaca NY, pp 1-4

Keim P, Price LB, Klevytska AM, Smith KL, Schupp JM, Okinaka R, Jackson PJ, Hugh-Jones ME (2000) Multiplelocus variable-number tandem repeat analysis reveals genetic relationships within Bacillus anthracis. J Bacteriol 182:2928-2936. https://doi.org/10.1128/JB.182.23.68626862.2000

Kobayashi RK, Gaziri LC, Vidotto MC (2010) Functional activities of the Tsh protein from avian pathogenic
Escherichia coli (APEC) strains. J Vet Sci 11:315-319. https://doi.org/10.4142/jvs.2010.11.4.315

Koelle DM, Corey L (2008) Herpes simplex: insights on pathogenesis and possible vaccines. Annu Rev Med 59:381-395. https://doi.org/10.1146/annurev.med.59. 061606.095540

Kruse H, Kirkemo AM, Handeland K (2004) Wildlife as source of zoonotic infections. Emerg Infect Dis 10:2067-2072. https://doi.org/10.3201/eid1012.040707

Kumaran S, Deivasigamani B, Alagappan KM, Sakthivel M, Prasad SG (2010) Isolation and characterization of Pseudomonas sp. KUMS3 from Asian sea bass (Lates calcarifer) with fin rot. World $\mathrm{J}$ Microbiol Biotechnol 26:359-363. https://doi.org/10.1007/s11274-009-0158-4

Liebana E, Carattoli A, Coque TM et al (2013) Public health risks of enterobacterial isolates producing extended-spectrum beta-lactamases or AmpC beta-lactamases in food and food-producing animals: an EU perspective of epidemiology, analytical methods, risk factors, and control options. Clin Infect Dis 56:1030-1037. https://doi.org/10. 1093/cid/cis 1043

Lindler L (2004) Virulence plasmids of Yersinia: characteristics and comparison. In: Funnel BE, Phillips GJ (eds) Plasmid biology. ASM Press, Washington, pp 423-437

Lista F, Faggioni G, Valjevac S et al (2006) Genotyping of Bacillus anthracis strains based on automated capillary 25-loci multiple locus variable-number tandem repeats analysis. BMC Microbiol 6:33. https://doi.org/10.1186/ 1471-2180-6-33

Macartney K, McIntyre P (2008) Vaccines for post-exposure prophylaxis against varicella (chickenpox) in children and adults. Cochrane Database Syst Rev. https://doi.org/10. 1002/14651858.CD001833.pub2

Maho A, Rossano A, Hachler H et al (2006) Antibiotic susceptibility and molecular diversity of Bacillus anthracis strains in Chad: detection of a new phylogenetic subgroup. J Clin Microbiol 44:3422-3425. https://doi.org/10.1128/ jcm.01269-06

Meier-Kolthoff JP, Hahnke RL, Petersen J et al (2014) Complete genome sequence of DSM 30083(T), the type strain (U5/41(T)) of Escherichia coli, and a proposal for delineating subspecies in microbial taxonomy. Stand Genomic Sci 9:2. https://doi.org/10.1186/1944-3277-9-2

Mellata M (2013) Human and avian extraintestinal pathogenic Escherichia coli: infections, zoonotic risks, and antibiotic resistance trends. Foodborne Pathog Dis 10:916-932. https://doi.org/10.1089/fpd.2013.1533

Mercia L (2001) Storey's guide to raising poultry, 1st edn. Storey Publishing, North Adams

Miller MM, Jarosinski KW, Schat KA (2005) Positive and negative regulation of chicken anemia virus transcription. J Virol 79:2859-2868. https://doi.org/10.1128/jvi.79.5. 2859-2868.2005

Mohammed MJ, Marston CK, Popovic T, Weyant RS, Tenover FC (2002) Antimicrobial susceptibility testing of Bacillus anthracis: comparison of results obtained by using the National Committee for Clinical Laboratory Standards broth microdilution reference and Etest agar gradient diffusion methods. J Clin Microbiol 40:1902-1907 
Moore JE, Corcoran D, Dooley JS et al (2005) Campylobacter. Vet Res 36:351-382. https://doi.org/10.1051/vetres: 2005012

Oglesbee BL (1997) Mycotic diseases. In: Altman RB, Clubb SL, Dorrestein GM, Quesenberry K (eds) Avian medicine and surgery. WB Saunders, Philadelphia, pp 323-331

Okutani A, Tungalag H, Boldbaatar B, Yamada A, Tserennorov D, Otgonchimeg I, Erdenebat A, Otgonbaatar D, Inoue S (2011) Molecular epidemiological study of Bacillus anthracis isolated in Mongolia by multiple-locus variablenumber tandem-repeat analysis for 8 loci (MLVA-8). Jpn J Infect Dis 64:345-348

Ortatatli M, Karagoz A, Percin D, Kenar L, Kilic S, Durmaz R (2012) Antimicrobial susceptibility and molecular subtyping of 55 Turkish Bacillus anthracis strains using 25-loci multiple-locus VNTR analysis. Comp Immunol Microbiol Infect Dis 35:355-361. https://doi.org/10.1016/ j.cimid.2012.02.005

Palaniappan RU, Zhang Y, Chiu D, Torres A, Debroy C, Whittam TS, Chang YF (2006) Differentiation of Escherichia coli pathotypes by oligonucleotide spotted array. J Clin Microbiol 44:1495-1501. https://doi.org/10.1128/ jcm.44.4.1495-1501.2006

Panigrahy B, Senne DA, Pedersen JC, Shafer AL, Pearson JE (1996) Susceptibility of pigeons to avian influenza. Avian Dis 40:600-604. https://doi.org/10.2307/1592270

Perkins LE, Swayne DE (2002) Pathogenicity of a Hong Kongorigin H5N1 highly pathogenic avian influenza virus for emus, geese, ducks, and pigeons. Avian Dis 46:53-63. https://doi.org/10.1637/0005-2086(2002)046[0053: poahko]2.0.co;2

Pilo P, Perreten V, Frey J (2008) Molecular epidemiology of Bacillus anthracis: determining the correct origin. Appl Environ Microbiol 74:2928-2931. https://doi.org/10.1128/ aem.02574-07

Quinn PJ, Markey BK, Leonard FC, Fitzpatrick ES, Fanning S (2015) Chicken anaemia virus infection. In: Concise review of veterinary microbiology, 2nd edn. Wiley, New York, p 146

Raue R, Schmidt V, Freick M, Reinhardt B, Johne R, Kamphausen L, Kaleta EF, Muller H, Krautwald-Junghanns ME (2005) A disease complex associated with pigeon circovirus infection, young pigeon disease syndrome. Avian Pathol 34:418-425. https://doi.org/10.1080/ 03079450500267825

Reich F, Atanassova V, Klein G (2013) Extended-spectrum $\beta$ lactamase- and AmpC-producing enterobacteria in healthy broiler chickens, Germany. Emerg Infect Dis 19:1253-1259. https://doi.org/10.3201/eid1908.120879

Robins-Browne R, Hartland E (2003) Yersinia species. In: Marianne DM, Bier JW (eds) International handbook of foodborne pathogens. CRC Press, New York, pp 323-355

Rosario CC, Puente JL, Verdugo-Rodriguez A, Anderson RC, Eslava CC (2005) Phenotypic characterization of $i p a H+$ Escherichia coli strains associated with yolk sac infection. Avian Dis 49:409-417. https://doi.org/10.1637/ 7323-010705r.1

Ryan KJ, Ray CG (2004) Sherris medical microbiology: an introduction to infectious diseases, 4th edn. McGraw Hill, New York, NY

Schaberg DR, Culver DH, Gaynes RP (1991) Major trends in the microbial etiology of nosocomial infection. Am J Med 91:72s-75s. https://doi.org/10.1016/0002-9343(91)90346Y

Schat KA (2009) Chicken anemia virus. Curr Top Microbiol Immunol 331:151-183. https://doi.org/10.1007/978-3540-70972-5_10

Schiffer JT, Mayer BT, Fong Y, Swan DA, Wald A (2014) Herpes simplex virus-2 transmission probability estimates based on quantity of viral shedding. J R Soc Interface 11:20140160. https://doi.org/10.1098/rsif.2014.0160

Spahr C, Knauf-Witzens T, Vahlenkamp T, Ulrich RG, Johne R (2018) Hepatitis E virus and related viruses in wild, domestic and zoo animals: a review. Zoonoses Public Health 65:11-29. https://doi.org/10.1111/zph.12405

Stathopoulos C, Provence DL, Curtiss R (1999) Characterization of the avian pathogenic Escherichia coli hemagglutinin Tsh, a member of the immunoglobulin A proteasetype family of autotransporters. Infect Immun 67:772-781

Thomas NJ, Hunter DB, Atkinson CT (2007) Infectious diseases of wild birds. Blackwell Publishing, Ames

Turnbull PC, Sirianni NM, LeBron CI, Samaan MN, Sutton FN, Reyes AE, Peruski LF Jr (2004) MICs of selected antibiotics for Bacillus anthracis, Bacillus cereus, Bacillus thuringiensis, and Bacillus mycoides from a range of clinical and environmental sources as determined by the Etest. J Clin Microbiol 42:3626-3634. https://doi.org/10. 1128/jcm.42.8.3626-3634.2004

Uma B, Prabhakar K, Rajendran S, Kavitha K, Sarayu YL (2009) Antibiotic sensitivity and plasmid profiles of Escherichia coli isolated from pediatric diarrhea. J Glob Infect Dis 1:107-110. https://doi.org/10.4103/0974-777x. 56255

Vandamme P, Dewhirst FE, Paster BJ, Stephen LW (2006) Bergey's manual of systematic bacteriology, vol 2, part C (The Proteobacteria), 2nd edn. Springer Science \& Business Media, New York, pp 1147-1160

Winkler ML, Papp-Wallace KM, Bonomo RA (2015) Activity of ceftazidime/avibactam against isogenic strains of Escherichia coli containing KPC and SHV beta-lactamases with single amino acid substitutions in the Omega-loop. J Antimicrob Chemother 70:2279-2286. https://doi.org/10. 1093/jac/dkv094

Zhang Y, Laing C, Steele M, Ziebell K, Johnson R, Benson AK, Taboada E, Gannon VPJ (2007) Genome evolution in major Escherichia coli O157:H7 lineages. BMC Genomics 8:121. https://doi.org/10.1186/1471-2164-8-121 